\title{
Coupling Finite Element Analysis and the Theory of Critical Distances to Estimate Critical Loads in Al6060-T66 Tubular Beams Containing Notches
}

\author{
Marcos Sánchez, Sergio Cicero* * B Borja Arroyo® and José Alberto Álvarez \\ LADICIM (Laboratory of Materials Science and Engineering), University of Cantabria, E.T.S. de Ingenieros de \\ Caminos, Canales y Puertos, Av/Los Castros 44, 39005 Santander, Spain; marcos.sanchez@unican.es (M.S.); \\ borja.arroyo@unican.es (B.A.); alvareja@unican.es (J.A.Á.) \\ * Correspondence: ciceros@unican.es; Tel.: 0034-942-200917
}

Received: 29 September 2020; Accepted: 17 October 2020; Published: 20 October 2020

check for updates

\begin{abstract}
This paper validates a methodology for the estimation of critical loads in tubular beams containing notch-type defects. The methodology is particularized for the case of A16060-T66 tubular cantilever beams containing U-shaped notches. It consists in obtaining the stress field at the notch tip using finite element analysis (FEA) and the subsequent application of the theory of critical distances (TCD) to derive the corresponding critical load (or load-bearing capacity). The results demonstrate that this methodology provides satisfactory predictions of fracture loads.
\end{abstract}

Keywords: critical load; fracture; tubular cantilever beam; U-notch; theory of critical distances

\section{Introduction}

Tubular sections are widely used in engineering applications such as transport systems (e.g., tubes, pipelines), naval and aeronautical engineering, offshore equipment, or lifting systems (e.g., cranes), among others. These structural solutions have been demonstrated to have great strength against different types of loading conditions such as torsion, compression, or multiaxial bending. In addition, their specific shape has proved to be an adequate solution for structures exposed to wind, water, or wave loads, and they are less prone to corrosion processes, as they do not tend to generate local accumulations of water. With all this, it is of great importance from an engineering perspective to be able to estimate the critical loads of this kind of structures, especially when they contain defects.

In the field of structural integrity, the analysis of defects plays an important role in ensuring the safety of structural components. Structural integrity procedures (e.g., [1-3]) are able to evaluate components containing cracks, combining fracture and plastic collapse analyses. However, in many cases, the structures present defects with finite radii on the tip. These defects are generally named notches, and if they are assessed as crack-like defects using standard methodologies (traditionally based on fracture mechanics [4,5]), the results tend to be over-conservative. This is caused by the fact that notches generate more relaxed stress fields at their tip (when compared to those generated by cracks). Apparently, the material develops a higher fracture resistance (usually referred to as the apparent fracture toughness) than that developed in cracked conditions (fracture toughness). Therefore, it is necessary to provide structural assessment methodologies that are capable of taking the notch effect into account, providing accurate predictions of the resulting critical loads. Different works (e.g., [6-11]) dealing with the structural integrity of tubular sections may be found in literature, although failure processes (e.g., plastic collapse, buckling) and defect types (e.g., cracks, cutouts) are different to those considered in this work.

In this sense, when dealing with notch assessments, there are two main types of criteria: the global criterion (based on the use of a notch stress intensity factor, analogously to ordinary fracture mechanics), 
and local criteria (based on the study of stress or strain fields around the notch tip). Among the latter, the theory of critical distances (TCD) stands out, and its applicability in fracture assessments has been widely reported in the literature for a variety of materials (such as polymers [12,13], metals [14,15], composites [16], or ceramics [17,18]). Moreover, the TCD has also been validated to analyze phenomena such as fatigue [19] or environmentally assisted cracking [20] and has been applied to different length scales $[19,21,22]$.

The TCD is actually a group of methodologies initially proposed in the mid-twentieth century by Neuber [23] and Peterson [24] to predict the fatigue behavior of structural components containing notches. All these methodologies have in common the use of two additional parameters: a material length parameter called the critical distance $(L)$, which is defined by Equation (1), and a material strength parameter named the inherent strength $\left(\sigma_{0}\right)$. In fracture analysis, both parameters are directly related with the material fracture resistance $\left(K_{m a t}\right)$ through Equation (1).

$$
L=\frac{1}{\pi}\left(\frac{K_{m a t}}{\sigma_{0}}\right)^{2}
$$

For brittle materials (e.g., ceramics) or quasi-brittle materials (e.g., many fiber-reinforced composites), the inherent material strength is equal or very close to the corresponding ultimate tensile strength $\left(\sigma_{u}\right)$. Otherwise, $\sigma_{0}$ tends to be higher than $\sigma_{u}$, with this tendency being more pronounced as long as plasticity is developed in the vicinity of the notch. In such cases, $\sigma_{o}$ has to be determined (calibrated) through experimental tests of specimens containing notches with different radii, or through a combination of experimental tests and finite element (FE) modeling.

Within the different approaches proposed by the TCD, the point method (PM) stands out for its simplicity, and provides similar results to other TCD methodologies, such as the line method, the area method, or the volume method, among others [19]. According to the PM criterion, fracture occurs when the stress equates the inherent strength, $\sigma_{0}$, at a distance equal to $L / 2$ from the defect tip. The mathematical expression is given by Equation (2):

$$
\sigma\left(\frac{L}{2}\right)=\sigma_{0}
$$

Thus, the PM allows the fracture behavior of notched components to be analyzed by simply knowing $L$ together with the (linear elastic) stress field at the notch tip. The evolution of FE tools allows the stress distribution at a stress concentrator to be more easily determined, something that has allowed extensive validation of the TCD methodologies [19]. However, this validation has been strongly focused on fracture mechanics notched specimens (e.g., CT and single edge notched bend (SENB) samples). In this context, this paper attempts to validate the application of the TCD (coupled with FE analyses) on a larger scale in real structural components (in this case, tubular cantilever beams containing U-notches).

With all of this, Section 2 presents the material and methods, Section 3 gathers the results obtained experimentally and through the TCD-FE analysis, together with the corresponding discussion, and Section 4 summarizes the main conclusions.

\section{Materials and Methods}

\subsection{Materials}

The material employed in the present study is a 6060-T66 aluminum alloy. It belongs to the wrought aluminum-magnesium-silicon alloys (6xxx series), and it has been additionally solution heat-treated and artificially aged (T66). This alloy is especially optimized for extrusion processes and develops good tensile strength. It has remarkable corrosion resistance and good weldability. It is commonly used in engineering applications (e.g., railway, automotive industry, building construction, etc.). 
In order to carry out the experimental program, four $1.8 \mathrm{~m}$ long tubular beams were employed. Two of them had an outer diameter of $312 \mathrm{~mm}$ and $6 \mathrm{~mm}$ thickness, with the other two beams having an outer diameter of $260 \mathrm{~mm}$ and $5 \mathrm{~mm}$ thickness. Table 1 gathers the nominal chemical composition of this aluminum alloy [25].

Table 1. Chemical composition (nominal) of Al6060-T66 [25].

\begin{tabular}{ccccccccc}
\hline $\mathbf{S i}$ & $\mathbf{F e}$ & $\mathbf{C u}$ & $\mathbf{M n}$ & $\mathbf{M g}$ & $\mathbf{C r}$ & $\mathbf{Z n}$ & $\mathrm{Ti}$ & Al \\
\hline $0.30-0.60$ & $0.10-0.30$ & $\leq 0.10$ & $\leq 0.10$ & $0.35-0.60$ & $\leq 0.05$ & $\leq 0.15$ & $\leq 0.10$ & balance \\
\hline
\end{tabular}

\subsection{Methods}

The present study proposes a methodology for the analysis of tubular cantilever beams containing (circumferential) through thickness U-notches by applying the TCD. This requires completing experimental tests and FE simulations.

Regarding the experimental program, three of the tubes mentioned above were conducted to failure through bending tests, but previously both fracture and tensile tests were performed in order to characterize the material. Fracture and tensile specimens were machined from the remnant fourth tube (with an outer diameter of $260 \mathrm{~mm}$ and $5 \mathrm{~mm}$ thickness).

Three tensile tests were conducted according to the ASTM E8M standard [26]. Figure 1 shows the dimensions of the samples that were machined in the longitudinal direction. The tests were carried out with a loading rate of $5 \mathrm{~mm} / \mathrm{min}$.

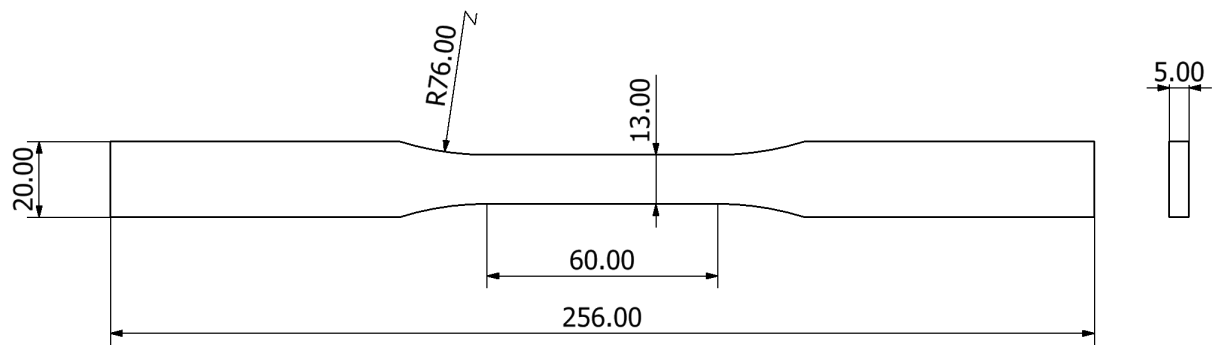

Figure 1. Tensile test specimens. Dimensions in $\mathrm{mm}$.

Subsequently, the fracture behavior of AL6060-T66 was characterized. A total of nine SENB specimens were tested following ASTM E1820 [27]. Three specimens for each notch radii were obtained in LC orientation: the opening stresses act in the longitudinal direction of the pipe, and the defect propagates circumferentially. The notch radii considered in this work are $0 \mathrm{~mm}$ (crack-like defect), $1 \mathrm{~mm}$, and $2 \mathrm{~mm}$. Notches of finite radius $(1 \mathrm{~mm}$ and $2 \mathrm{~mm}$ ) were obtained by machining, whereas crack-like defects were generated by fatigue pre-cracking according to ASTM E1820. Figure 2 shows a schematic of the specimen used in the fracture characterization. It can be noticed that the width is slightly smaller than the tube thickness due to the need to have prismatic samples. The loading rate was $10 \mathrm{~mm} / \mathrm{min}$.

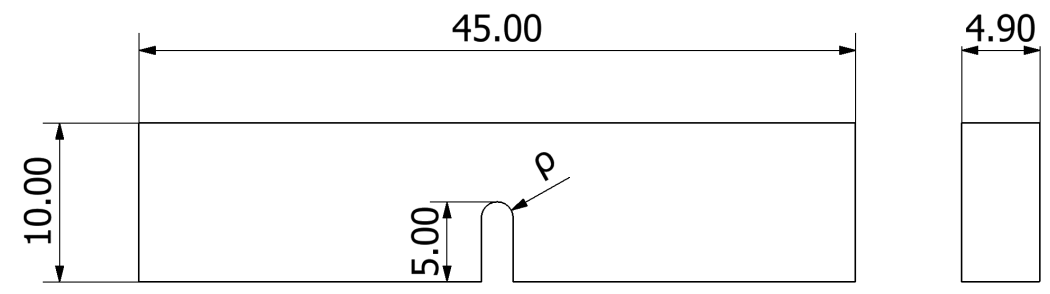

Figure 2. Schematic of fracture single edge notched bend (SENB) specimens. Dimensions in mm. 
To conclude with the experimental works, the remnant three tubular cantilever beams were prepared to be tested. Through-thickness circumferential U-notches were machined at a distance of approximately $350 \mathrm{~mm}$ from one of the tube ends. In order to obtain a fixed support, the same tube end was introduced $330 \mathrm{~mm}$ in reinforced concrete. Figure 3 shows an image of the experimental setup, Figure 4 represents a schematic of the notched tubular cantilever beams, and Table 2 gathers the geometry of both the tubes and the notches.

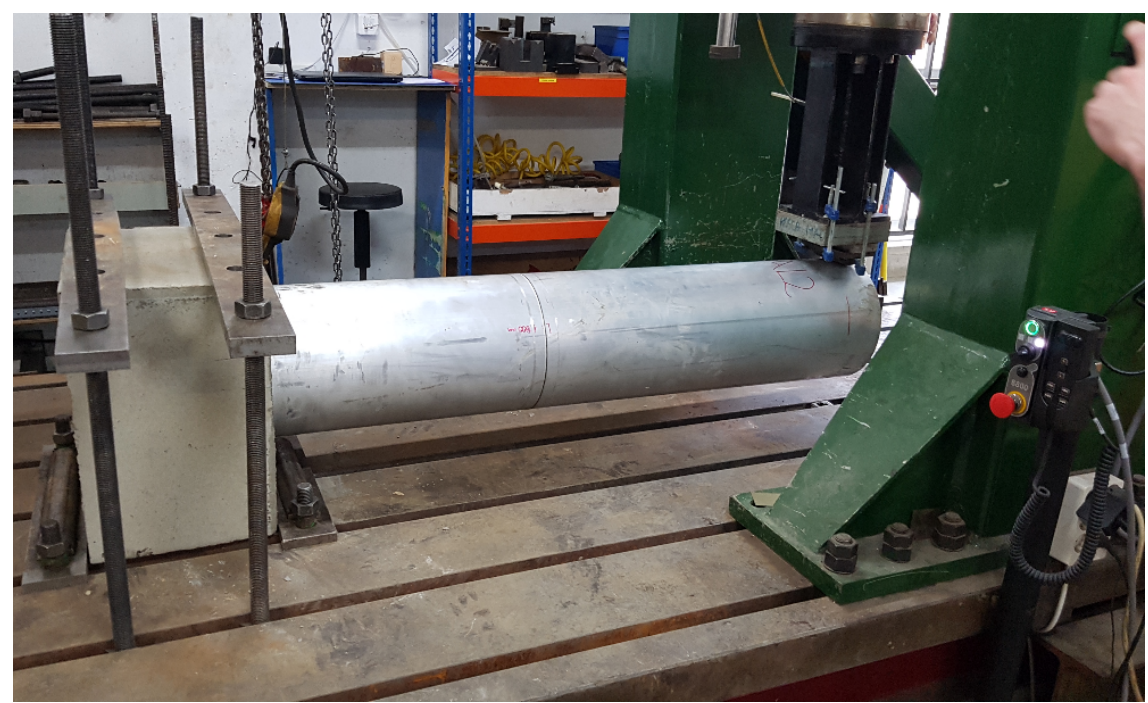

Figure 3. Experimental setup.

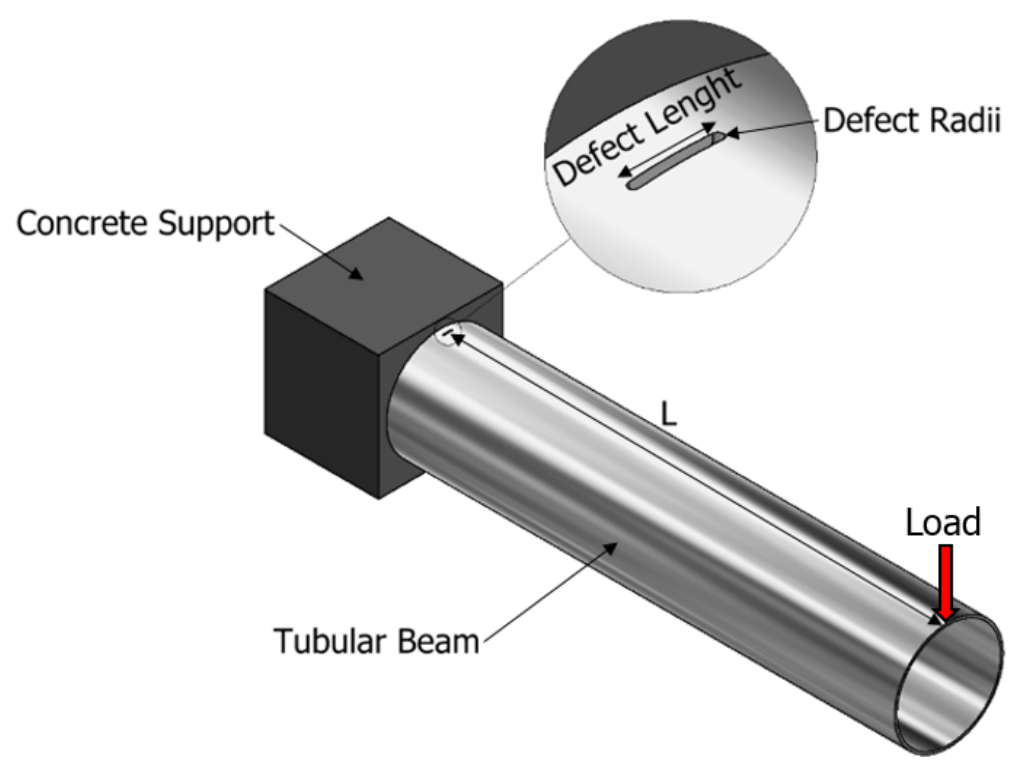

Figure 4. Schematic of the tubular cantilever beams containing a U-notch close to the fixed support.

Table 2. Geometrical parameters of the tubes and their corresponding U-notch: $\varnothing$, outer diameter; $B$, tube thickness; $D$, distance from concrete support to notched section; $L$, distance from applied load to notched section; $2 a$, defect length; $\rho$, defect radius. Dimensions in $\mathrm{mm}$.

\begin{tabular}{cccccccc}
\hline Tube & Material & $\varnothing$ & $\boldsymbol{B}$ & $\boldsymbol{D}$ & $\boldsymbol{L}$ & $\mathbf{2 a}$ & $\boldsymbol{\rho}$ \\
\hline AL1 & AL6060-T66 & 312 & 6.0 & 30.4 & 1451 & 27.2 & 0.8 \\
AL2 & AL6060-T66 & 312 & 6.0 & 27.0 & 1448 & 27.2 & 1.5 \\
AL3 & AL6060-T66 & 260 & 5.0 & 21. & 1452 & 45.3 & 0.8 \\
\hline
\end{tabular}


In order to obtain the experimental critical loads (load-bearing capacity), the tubes were set up in the testing bench, ensuring that the solid concrete block was totally fixed with screws avoiding any kind of movement. A single vertical load was applied at the free edge with a testing rate of $10 \mathrm{~mm} / \mathrm{min}$, while a calibrated laser comparator measured the resulting deflection.

As explained above, the application of the PM requires the stress field around the defect tip to be determined. With this aim, FE analyses were carried out. The simulations were performed in linear elastic conditions using the finite element software ANSYS 19.2 (Ansys Inc, Canonsburg, PA, USA) both in the SENB specimens and the cantilever beams.

The simulation of the SENB specimens (Figure 5a) was performed using a structured mesh composed by 20-node hexahedron elements, as shown in Figure 5b. The area surrounding the notch tip was discretized using a much finer mesh, because of the higher stress gradient generated in that zone. For each notch radius, the stress-distance curves were finally obtained in the middle line of the fracture section and for the corresponding average value of the critical loads. The stresses used in the analyses are the corresponding maximum principal stresses, which, in these particular structural conditions, act in the longitudinal direction of the tubular beams.

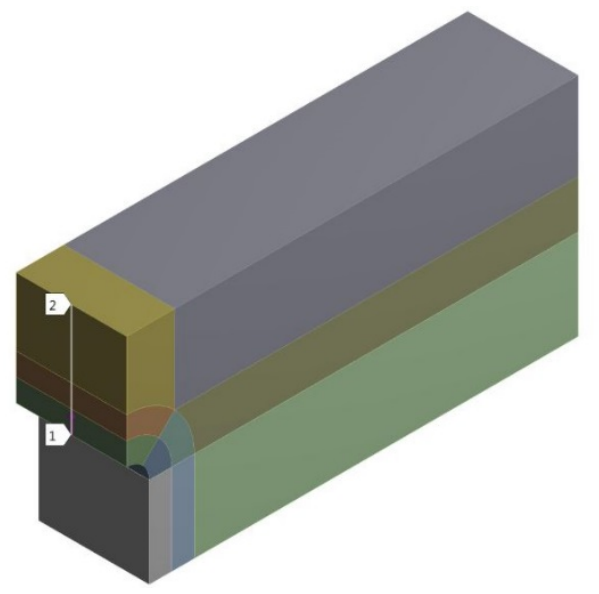

(a)

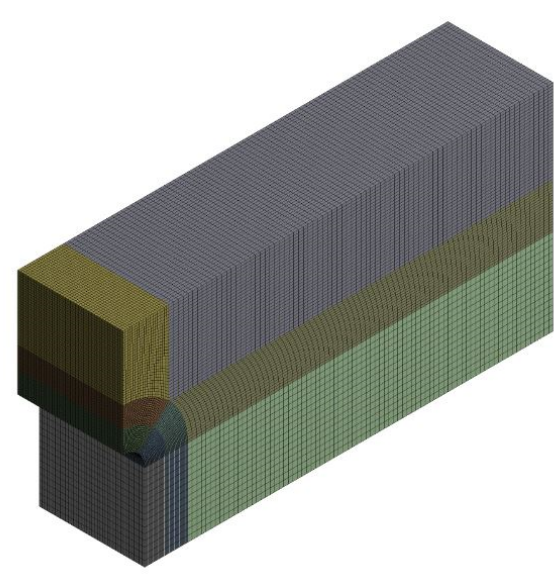

(b)

Figure 5. Geometry of the model used in finite element (FE) simulations, showing the middle line on the fracture section (a) and the generated mesh (b).

Once the stress-distance curves for each notch radius were determined, the PM was applied to calibrate the material parameters. When PM is used, it is sufficient to obtain the cutoff point between the different curves, which theoretically corresponds to the coordinates $\left(L / 2, \sigma_{o}\right)$, as shown in Figure 6 .

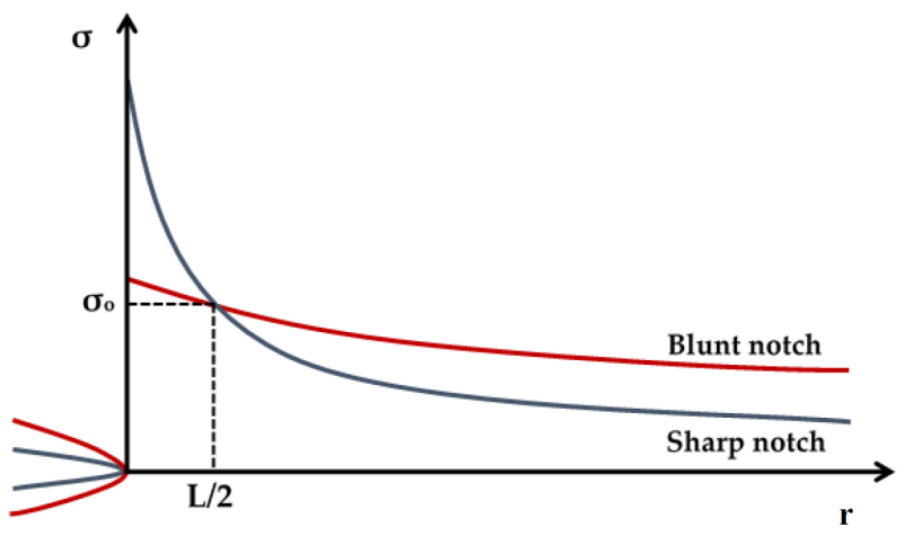

Figure 6. Obtaining theory of critical distances (TCD) parameters using the stress-distance curves. 
Finally, the three cantilever tubular beams were modeled (see an example in Figure 7). Again, a structured mesh composed by 20-node hexahedron elements was used. The notch region was partitioned in order to generate a refined mesh, also ensuring 20 elements along the tube thickness. The simulation was performed with just a half of the tube because of the symmetry conditions, applying the load at the free end of each beam. The part of the tube fixed in the concrete block had all the movements restricted, and the points of the tube located in the symmetry plane could only have displacements in such a plane. Here, it is important to notice that the critical load of the complete tubular beam is twice the critical load of the model. A path was created on each tube, starting at the notch root, at half of the tube thickness and along the circumferential direction. Thus, the stress-distance curve (along the corresponding path) was obtained for each tube under the load being applied. Finally, the estimated critical load (or load-bearing capacity) was that for which Equation (2) was satisfied.

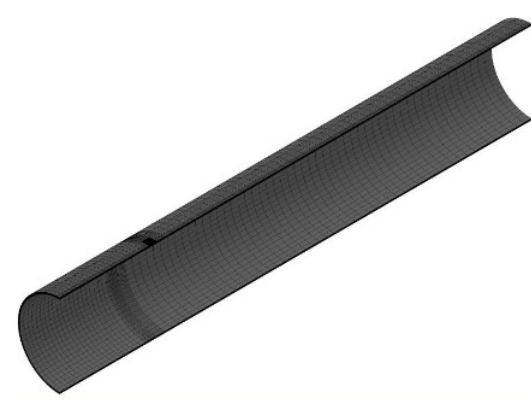

(a)
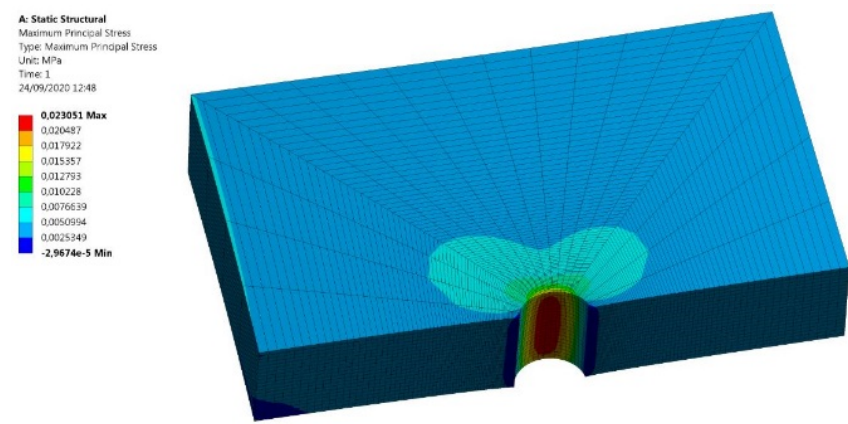

(b)

Figure 7. (a) Mesh employed in the FEA (finite element analysis) of the tubular beams; (b) detail of the notch tip.

\section{Results}

The main tensile properties of the Al6060-T66 being used are gathered in Table 3, with $E$ being the Young's modulus, $\sigma_{0.2}$ being the proof strength, $\sigma_{u}$ being the ultimate tensile strength, and $\varepsilon_{\max }$ being the strain under maximum load.

Table 3. Mechanical properties (mean and standard deviation).

\begin{tabular}{ccccc}
\hline Material & $E(\mathbf{M P a})$ & $\sigma_{0.2}(\mathbf{M P a})$ & $\sigma_{u}(\mathbf{M P a})$ & $\varepsilon_{\max }(\%)$ \\
\hline AL 6060 & $70,750 \pm 554$ & $215.0 \pm 1.7$ & $264.4 \pm 1.8$ & $11.60 \pm 0.31$ \\
\hline
\end{tabular}

Table 4 presents the experimental results of the fracture tests, with Figure 8 showing some representative examples of the experimental load-displacement curves obtained for each notch radius. Here, it is important to notice that the fracture resistance values obtained are high, even in cracked conditions. In this sense, Equation (3) provides a criterion to estimate the onset of the plane stress conditions [19], with $B$ being the thickness and $\sigma_{y}$ being the yield stress (the proof stress for the material being analyzed here). It is straightforward to derive that plane stress conditions are achieved for fracture resistance values above $26.7 \mathrm{MPam}^{1 / 2}$, approximately, so all the SENB specimens being tested are under plane stress conditions, explaining the high values of fracture resistance obtained here. This is also important to justify the scarce influence of the election of the tube selected for tensile and fracture characterization. As long as the two possible thicknesses ( $5 \mathrm{~mm}$ vs. $6 \mathrm{~mm}$ ) generate fully plane stress conditions, the influence of this dimension on the resulting fracture resistance may be considered to be negligible.

$$
K_{\text {Plane Stress }}=\sigma_{Y}(\pi B)^{1 / 2}
$$


Table 4. Experimental results obtained in SENB specimens. $K^{N}$ mat in cracked specimens correspond to the material fracture toughness $K_{m a t}$.

\begin{tabular}{|c|c|c|c|c|c|}
\hline Material & Specimen & $\rho(\mathrm{mm})$ & $\begin{array}{l}\text { Defect Length } \\
(\mathrm{mm})\end{array}$ & $\begin{array}{l}\text { Critical Load } \\
\text { (N) }\end{array}$ & $\begin{array}{c}K^{N}{ }_{m a t} \\
\left(\mathrm{MPa}^{\prime} \cdot \mathbf{m}^{1 / 2}\right)\end{array}$ \\
\hline \multirow{8}{*}{ AL6060-T66 } & $0-1$ & 0 & 4.23 & 1208.8 & 51.89 \\
\hline & $0-2$ & & 4.62 & 1341.6 & 59.42 \\
\hline & $1-1$ & 1 & 5.00 & 1235.8 & 96.53 \\
\hline & $1-2$ & & 5.00 & 1236.2 & 92.62 \\
\hline & $1-3$ & & 5.00 & 1226.7 & 103.56 \\
\hline & $2-1$ & 2 & 5.00 & 1296.1 & 125.49 \\
\hline & $2-2$ & & 5.00 & 1259.2 & 116.47 \\
\hline & $2-3$ & & 5.00 & 1259.2 & 130.03 \\
\hline
\end{tabular}

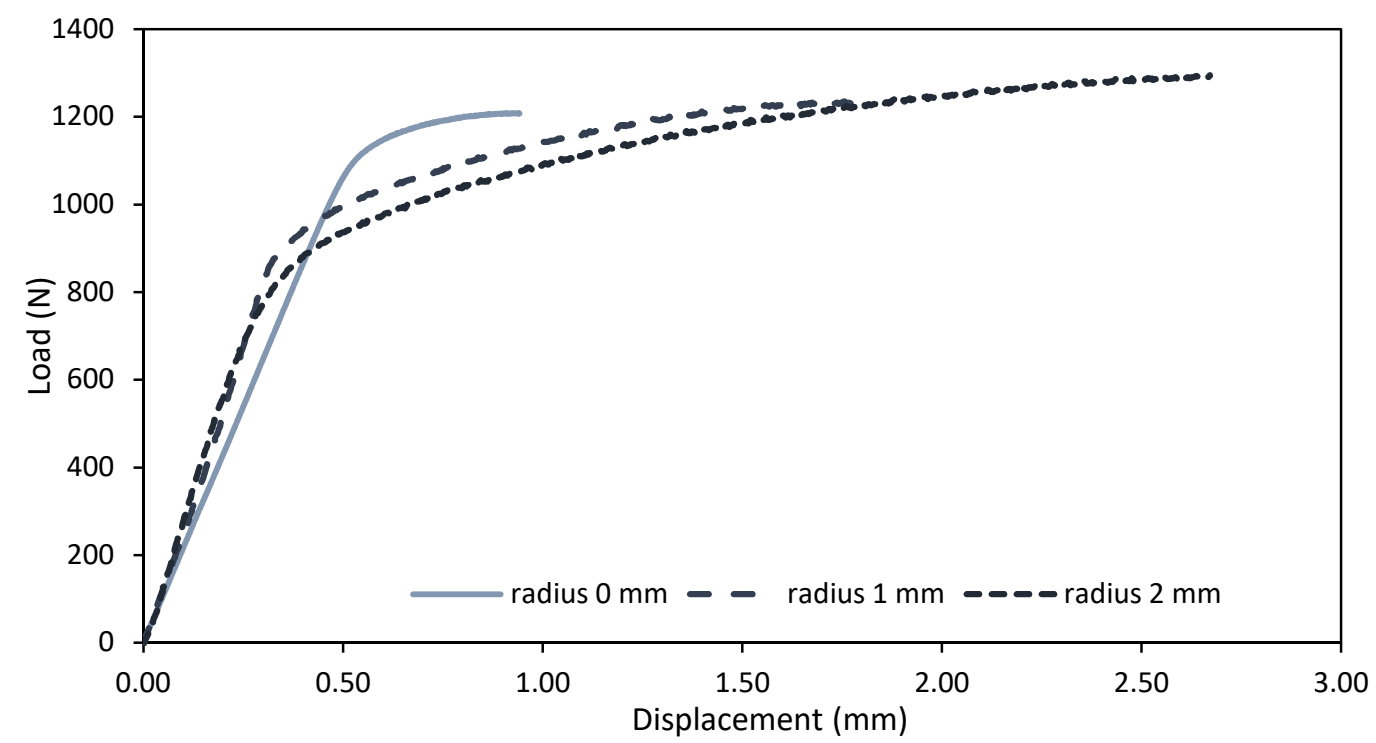

Figure 8. Load-displacement curves of some of the fracture tests.

The load-displacement curves of the structural tests performed on the notched cantilever beams are shown in Figure 9, while the corresponding values of the critical load (in terms of the experimental load-bearing capacity, $\mathrm{LBC}_{\mathrm{exp}}$ ) are presented in Table 5.

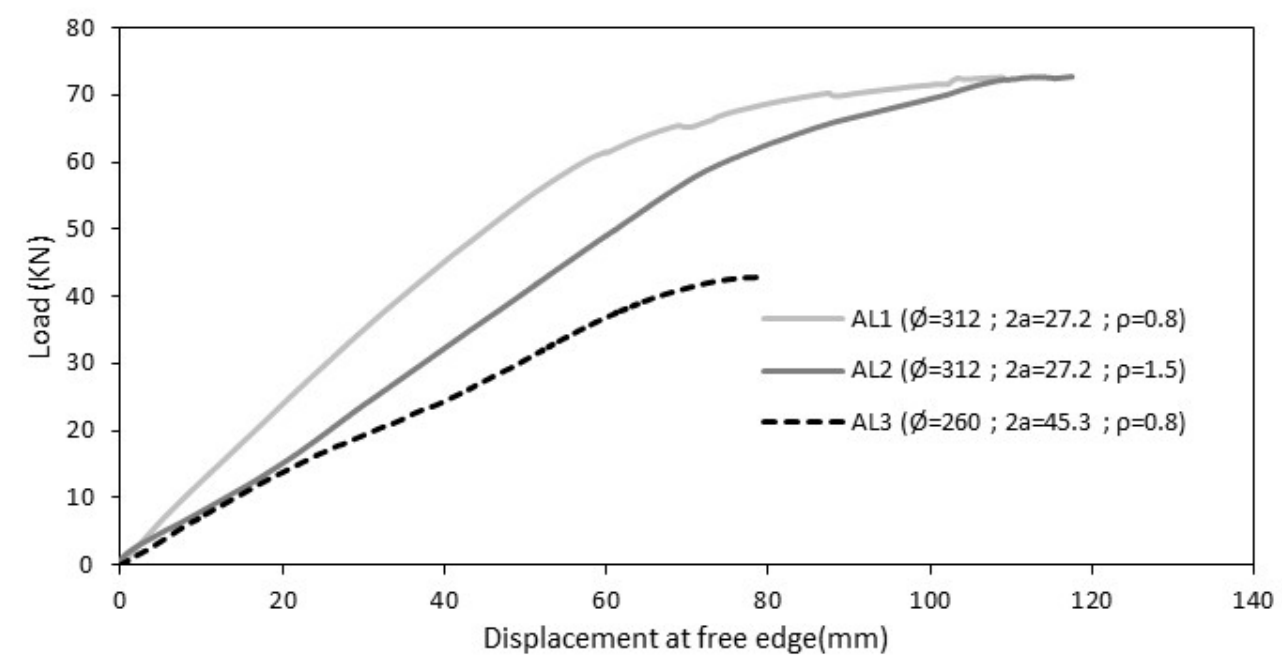

Figure 9. Load-displacement curves of the different tubular beam. 
Table 5. Values of $L$ and $\sigma_{o}$ obtained from calibration, together with the experimental and the estimated values of load-bearing capacity (LBC).

\begin{tabular}{ccccc}
\hline Tube & $\boldsymbol{L}(\mathbf{m m})$ & $\left.\sigma_{\boldsymbol{o}} \mathbf{( M P a}\right)$ & $\mathbf{L B C}_{\mathbf{e x p}}(\mathbf{k N})$ & $\mathbf{L B C}_{\text {est }}(\mathbf{k N})$ \\
\hline AL1 & & & 72.65 & 76.67 \\
AL2 & 0.22 & 920 & 72.75 & 87.62 \\
AL3 & & & 42.86 & 39.15 \\
\hline
\end{tabular}

Concerning the FE simulations, the stress-distance curves obtained in the fracture section of the SENB specimens are shown in Figure 10. When the PM is applied in more than two geometries, and the number of tests is limited, it can be observed that the different curves do not necessarily cross each other at the same point, as shown in Figure 6. Following the PM, and considering the inherent scatter of fracture processes, a much larger number of specimens per notch radius would be needed to obtain a single crossing point. For this reason, the material parameters, gathered in Table 5, have been obtained in this work as the average of the different cutoff points, the essential assumption of the PM being reasonably fulfilled. Analogously, Figure 11 shows the stress-distance curves corresponding to the different tubular beams when a load of $1 \mathrm{~N}$ is applied in the free edge.

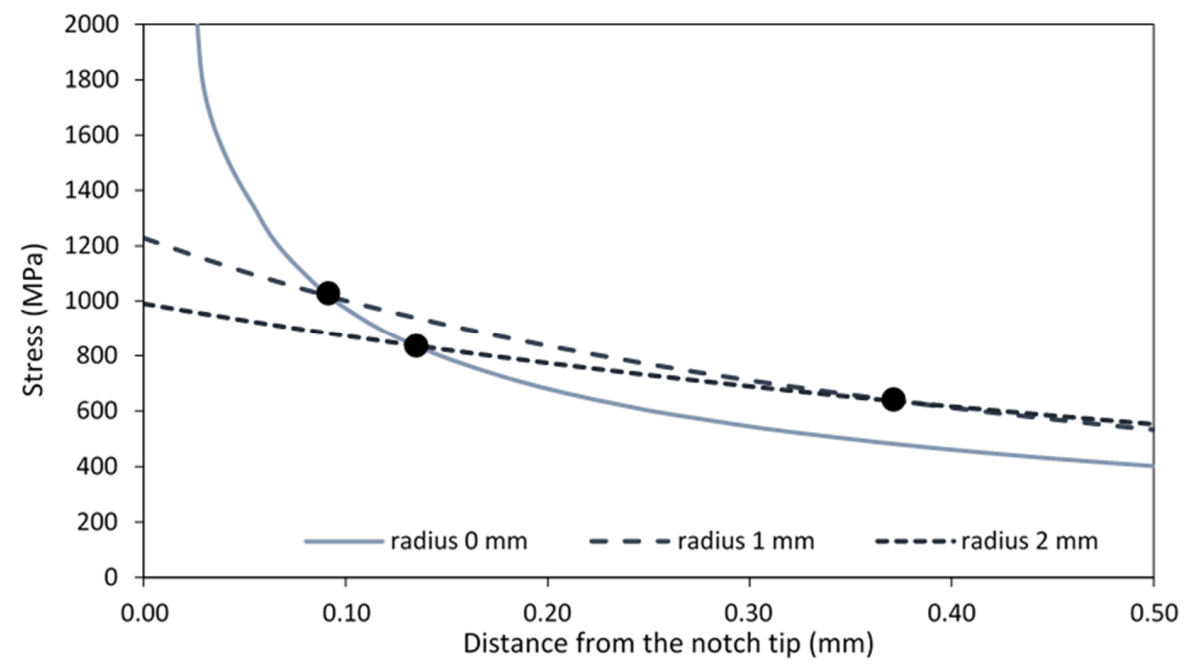

Figure 10. Stress-distance curves at critical load in SENB specimens. The solid circles correspond to the cutoff points.

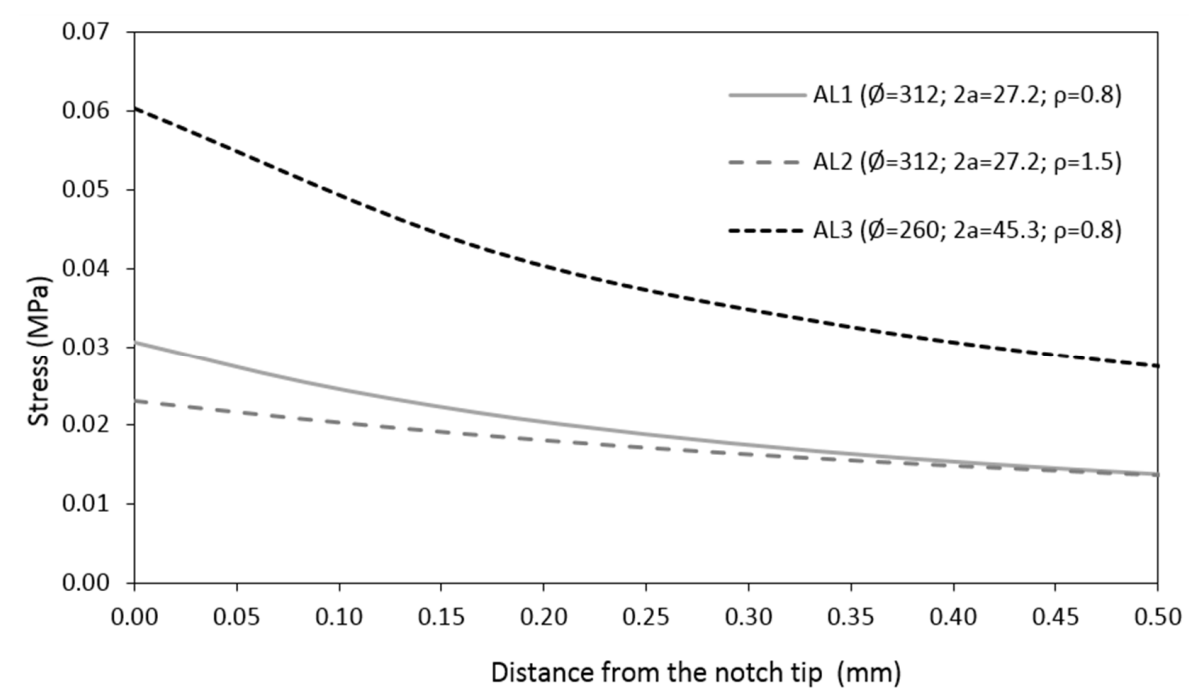

Figure 11. Stress-distance curves in tubular beams when applying a unit load $(1 \mathrm{~N})$ at the free end. 
Once the experimental results and the FE modeling have been presented, Table 5 also shows the estimations of the load-bearing capacity $\left(\mathrm{LBC}_{\mathrm{est}}\right)$ for each tube.

Figure 12 compares the experimental results and the corresponding TCD-FE estimations, showing acceptable predictions of the load-bearing capacity. All the results are basically in the $\pm 20 \%$ scatter band, which is generally accepted in fracture research [19,28-30], with an average overestimation of the LBC of $+5.7 \%$. This is also understandable, taking into consideration that this approach does not include any safety factor, something commonly used in structural integrity assessments. It can be noticed that the maximum deviation (+20\%) occurs in the tube with the largest notch radii $(\rho=1.5 \mathrm{~mm})$, which has the more pronounced nonlinear behavior (see Figure 9). It seems that although the TCD compensates nonlinearities with the calibration process (through $\sigma_{0}$ values larger than $\sigma_{u}$ ), the resulting LBC estimations may lose accuracy when the material's nonlinear behavior becomes more developed.

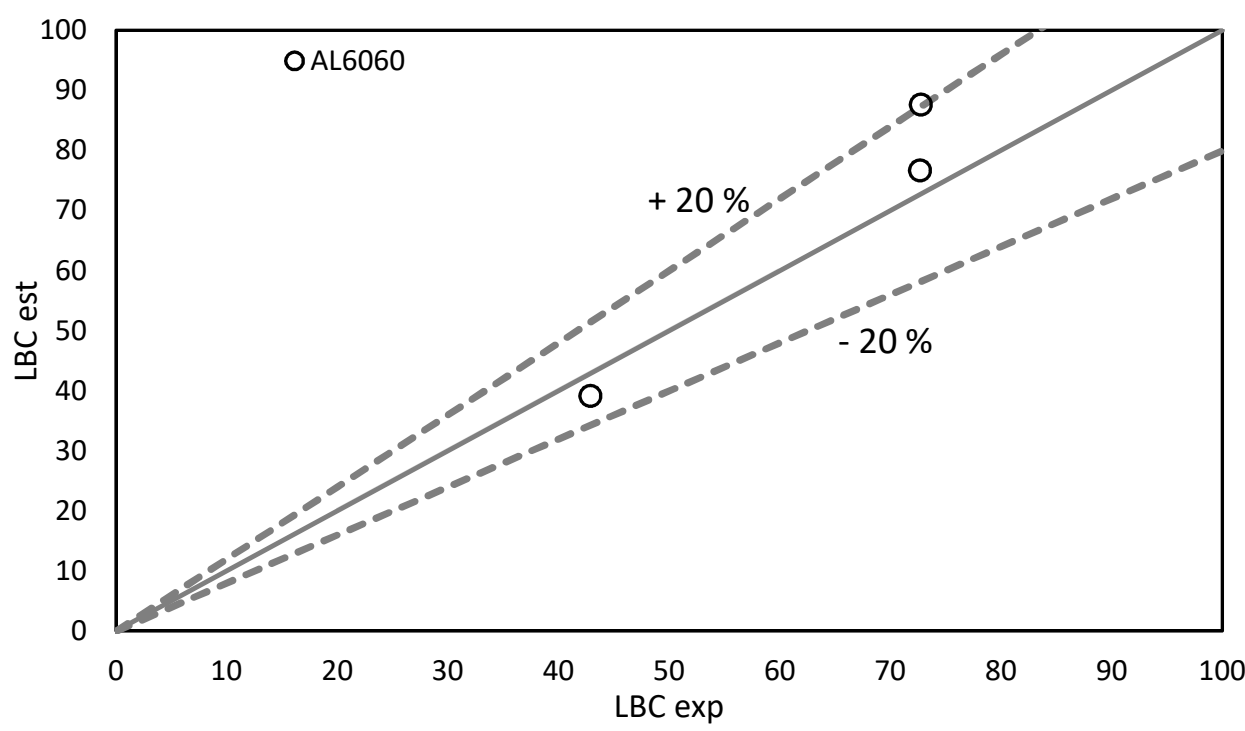

Figure 12. Comparison between the experimental results (LBCexp) and the resulting estimations (LBCest).

\section{Conclusions}

In this paper, a methodology for the estimation of critical loads in tubular beams containing U-notches has been validated. The methodology is based on the application of the theory of critical distances (TCD) through the point method (PM) and finite element (FE) linear elastic simulations. The methodology has been validated in three Al6060-T66 cantilever beams containing circumferential through thickness U-notches, providing specific validation beyond that reported in fracture mechanics specimens.

Tensile and fracture tests allowed the corresponding material mechanical properties to be estimated, and the combination of fracture tests on notched SENB specimens and FE analyses allowed the material critical distance and inherent strength to be calibrated.

With all this, FE simulations of the notched cantilever beams were performed, determining the estimations of the critical loads (or load-bearing capacities) as those loads for which the PM criterion was fulfilled.

The predicted critical loads represent acceptable estimations of the experimental critical loads, almost within the typical accepted scatter band for fracture processes $( \pm 20 \%)$, and with an average overestimation of $+5.7 \%$ (without any use of safety factors). The largest deviation $(+20.4 \%)$ was observed in the beam developing the most evident nonlinear behavior, thus being further away from the initial linear elastic nature of the TCD, which makes it harder to compensate by the calibration process of the material critical distance.

The methodology may be applied to other structural components containing any kind of notches. However, further validation is required to establish general conclusions about its accuracy. 
Author Contributions: Conceptualization, S.C.; methodology, S.C., M.S., B.A., and J.A.Á.; formal analysis, S.C and M.S.; investigation M.S., S.C., and B.A.; writing-original draft preparation, M.S.; writing-review and editing, M.S., S.C, B.A., and J.A.Á. All authors have read and agreed to the published version of the manuscript.

Funding: This research received funding from the Spanish Ministry of Science and Innovation, grant PGC2018-095400-B-I00 “Comportamiento en fractura de materiales compuestos nano-reforzados con defectos tipo entalla".

Conflicts of Interest: The authors declare no conflict of interest.

\section{References}

1. Kocak, M.; Webster, S.; Janosch, J.J.; Ainsworth, R.A.; Koers, R. FITNET Fitness-for-Service (FFS) Procedure; GKSS: Hamburg, Germany, 2008; Volume 1.

2. BS7910, Guide to Methods for Assessing the Acceptability of Flaws in Metallic Structures; British Standards Institution: London, UK, 2019.

3. R6: Assessment of the Integrity of Structures Containing Defects, Rev. 4; EDF Energy: Gloucester, UK, 2015.

4. Anderson, T.L. Fracture Mechanics: Fundamentals and Applications, 4th ed.; CRC Press-Taylor and Francis Group: Boca Raton, FL, USA, 2005.

5. Broek, D. Elementary Engineering Fracture Mechanics, 4th ed.; Martinus Nijhoff: Dordrecht, The Netherlands, 2012.

6. Stasiewicz, P. Analytical and Experimental Studies of Stability of Cylindrical Shells with a Cut-Out. Mech. Mech. Eng. 2013, 17, 167-176.

7. Staat, M. Local and global collapse pressure of longitudinally flawed pipes and cylindrical vessels. Int. J. Press. Vessel. Pip. 2005, 82, 217-225. [CrossRef]

8. Ahn, S.-H.; Nam, K.W.; Takahashi, K.; Ando, K. Comparison of experimental and finite element analytical results for the strength and the deformation of pipes with local wall thinning subjected to bending moment. Nucl. Eng. Des. 2006, 236, 140-155. [CrossRef]

9. Schenk, C.A.; Schuëller, G.I. Buckling analysis of cylindrical shells with cutouts including random boundary and geometric imperfections. Comput. Methods Appl. Mech. Eng. 2007, 196, 3424-3434. [CrossRef]

10. Yeh, M.-K.; Lin, M.-C.; Wu, W.-T. Bending buckling of an elastoplastic cylindrical shell with a cutout. Eng. Struct. 1999, 21, 996-1005. [CrossRef]

11. Alashti, R.A.; Rahimi, G.H.; Poursaeidi, E. Plastic limit load of cylindrical shells with cutouts subject to pure bending moment. Int. J. Press. Vessel. Pip. 2008, 85, 498-506. [CrossRef]

12. Cicero, S.; Madrazo, V.; Carrascal, I.A. Analysis of notch effect in PMMA using the Theory of Critical Distances. Eng. Fract. Mech. 2012, 86, 56-72. [CrossRef]

13. Taylor, D.; Merlo, M.; Pegley, R.; Cavatorta, M.P. The effect of stress concentrations on the fracture strength of polymethylmethacrylate. Mater. Sci. Eng. A 2004, 382, 288-294. [CrossRef]

14. Taylor, D. The theory of critical distances applied to the prediction of brittle fracture in metallic materials. Struct. Durab. Health Monit. 2005, 1, 145. [CrossRef]

15. Madrazo, V.; Cicero, S.; Carrascal, I.A. On the Point Method and the Line Method notch effect predictions in Al7075-T651. Eng. Fract. Mech. 2012, 79, 363-379. [CrossRef]

16. Ibáñez-Gutiérrez, F.T.; Cicero, S. Fracture assessment of notched short glass fibre reinforced polyamide 6: An approach from failure assessment diagrams and the theory of critical distances. Compos. Part B Eng. 2017, 111, 124-133. [CrossRef]

17. Cicero, S.; García, T.; Castro, J.; Madrazo, V.; Andrés, D. Analysis of notch effect on the fracture behaviour of granite and limestone: An approach from the Theory of Critical Distances. Eng. Geol. 2014, 177, 1-9. [CrossRef]

18. Castro, J.; Cicero, S.; Sagaseta, C. A Criterion for Brittle Failure of Rocks Using the Theory of Critical Distances. Rock Mech. Rock Eng. 2015, 49, 63-77. [CrossRef]

19. Taylor, D. The Theory of Critical Distances: A New Perspective in Fracture Mechanics; Elsevier: London, UK, 2007.

20. Gutiérrez, P.; Cicero, S.; Martínez, B.; Álvarez, J.A. A Theory of Critical Distances based methodology for the analysis of environmentally assisted cracking in steels. Eng. Fract. Mech. 2019, 214, 134-148.

21. Gallo, P.; Yan, Y.; Sumigawa, T.; Kitamura, T. Fracture Behavior of Nanoscale Notched Silicon Beams Investigated by the Theory of Critical Distances. Adv. Theory Simul. 2017, 1, 1700006. [CrossRef] 
22. Gallo, P.; Sapora, A. Brittle Failure of Nanoscale Notched Silicon Cantilevers: A Finite Fracture Mechanics Approach. Appl. Sci. 2020, 10, 1640. [CrossRef]

23. Neuber, H. Theorie der technischen Formzahl. Forsch. Auf. Dem. Geb. Des. Ing. A 1936, 7, 271-274. [CrossRef]

24. Peterson, R.E. Notch Sensitivity, Metal Fatigue; Sines, G., Lwaisman, J., Eds.; McGrawrHill: New York, NY, USA, 1959.

25. EN 573-1:2005, Aluminium and Aluminium Alloys-Chemical Composition and Form of Wrought Products; European Committee for Standardization: Brussels, Belgium, 2015.

26. ASTM E8/E8M-16ae1, Standard Test Methods for Tension Testing of Metallic Materials; ASTM International: West Conshohocken, PA, USA, 2016.

27. ASTM E1820-20, Standard Test Method for Measurement of Fracture Toughness; ASTM International: West Conshohocken, PA, USA, 2020.

28. Cicero, S.; Madrazo, V.; García, T.; Cuervo, J.; Ruiz, E. On the notch effect in load bearing capacity, apparent fracture toughness and fracture mechanisms of polymer PMMA, aluminium alloy Al7075-T651 and structural steels S275JR and S355J2. Eng. Fail. Anal. 2013, 29, 108-121. [CrossRef]

29. Cicero, S.; Madrazo, V.; García, T. On the assessment of U-shaped notches using Failure Assessment Diagrams and the Line Method: Experimental overview and validation. Theor. Appl. Fract. Mech. 2015, 80, 235-241. [CrossRef]

30. Berto, F.; Lazzarin, P. Recent developments in brittle and quasi-brittle failure assessment of engineering materials by means of local approaches. Mater. Sci. Eng. R Rep. 2014, 75, 1-48. [CrossRef]

Publisher's Note: MDPI stays neutral with regard to jurisdictional claims in published maps and institutional affiliations.

(C) 2020 by the authors. Licensee MDPI, Basel, Switzerland. This article is an open access article distributed under the terms and conditions of the Creative Commons Attribution (CC BY) license (http://creativecommons.org/licenses/by/4.0/). 